\title{
Hanging of a Blind Man
}

\author{
S Choudhury ${ }^{1}$, Ajitesh Pal*1, RK Das ${ }^{2}$ and HK Pratihari ${ }^{1}$ \\ ${ }^{1}$ Tripura State Forensic Science Laboratory, Agartala, India \\ ${ }^{2}$ Department of Forensic Medicine and Toxicology, Agartala Government Medical College, India
}

Submission: September 5, 2017; Published: September 08, 2017

*Corresponding author: Ajitesh Pal, Tripura State Forensic Science Laboratory, Agartala - 799015, India, Email: ajiteshp@rediffmail.com

\begin{abstract}
Life is a gift of God to live and grow for all human beings in the society. But people have been killing themselves by various means and killing by suicidal hanging is very common and more in comparison to other methods. As per National Crime Record Bureau (NCRB), MHA, Govt. of India every hour one student commits suicide in India and more men are ending their lives than women. But suicidal hanging by blind student is rarely reported and sufficient reference is also not available in the literature. In one case, the incident of suicidal hanging of a blind student was reported inside Impaired Vision Handicapped (IVH) boys' hostel campus. The blind victim in the night all alone collected hanging material (rope) and chair to reach the hanging point and committed suicide. The unexpected incident surprised everybody for the power of intuition and strength of inner vision of the blind boy. The post analysis of the undisturbed hanging spot, autopsy report and mysterious suicidal note (Braille dots) with available admitted writing (Braille dots) of the deceased could corroborate and establish the incident of suicide beyond doubt.
\end{abstract}

Keywords: Blind student hanging; Spot analysis, Autopsy report, Suicidal note (Braille writing), mental distress

\section{Introduction}

Life is a valuable gift of God to live a full bloom human being in the society and to fight against all odds for existence. But people are killing themselves for various causes adopting different methods to end their lives. Suicide is one of them. The word "suicide" literally means to kill oneself. Suicide methods are categorised as violent or non-violent. Violent methods include hanging, drowning, and shooting while poisoning and gassing are non-violent methods [1]. There are various methods of killing oneself but suicidal hanging is preferable since it is painless. It takes less time and easy to locate the place (indoor/ outdoor) and hanging materials like rope, towel, dupatta (long dress material), sari etc. are easily available [2,3]. The various causes of hanging are capsulized in (Figure 1).

The incident of suicide is alarming in the world and about 8 lacs people commit suicide every year as per WHO report, 2012 [4]. Out of total suicide, males contribute 1.8 times more than females. Further, the suicidal rate per 1 lac population is 34.6 in Sri Lanka being the highest in the world followed with Guyana having 30.6 as per WHO report, 2015 [5]. Moreover, there are many instances of suicide but a blind committing suicide is rare except few cases [6]. The suicide of a blind man is difficult and unbelievable. But in this case, the incident might have occurred due to despair or dejection. The case has been discussed in detail.

\section{Observations}

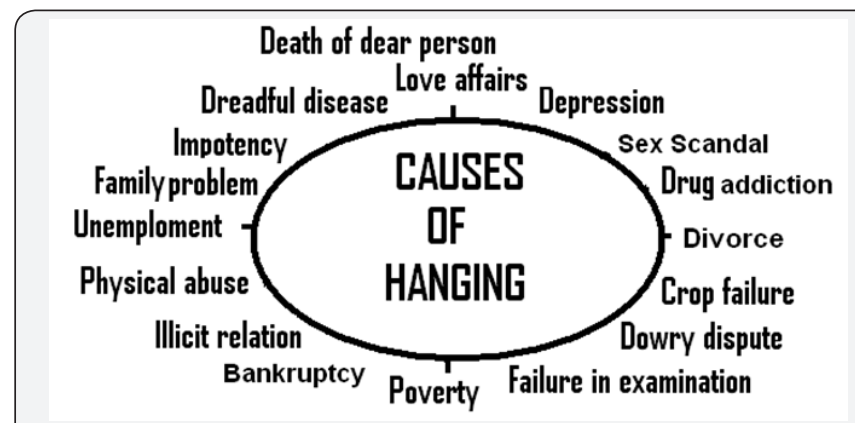

Figure 1: Showing the causes of hanging.

The suicidal hanging spot was examined by forensic team, medico-legal expert along with investigating officer in undisturbed condition of the hanging body. Observations made are shown in (Figures 2-6).

\section{Autopsy Findings}

External: The deceased (blind boy) is male age about 17year, measuring $167 \mathrm{~cm}$ height, $51 \mathrm{~kg}$ weight having average built. Rigor mortis present all over the body. PM lividity is present over the back of the trunk and lower parts of all limbs except the areas of contact flattening and is fixed. No sign of decomposition seen over the body. Eyes are closed. Eye balls are small and 
shrunken. Corneas are small. Mouth is partially open. Tongueno abnormality detected. Frenula in the oral cavity are found intact. Saliva stain is present on the left side collar of T-shirt. Penis-Prepuce retractable. No injury present. Smegma absent. Anus-dilated having blood stained discharge and faecal matter. One dark brown coloured, continuous, parchmentised, grooved ligature mark, obliquely placed, having maximum width of 1.2 $\mathrm{cm}$ is present around the whole circumference of neck. The ligature mark is situated $1 \mathrm{~cm}$ below the tip of right mastoid process, $6 \mathrm{~cm}$ below the chin, $11 \mathrm{~cm}$ above suprasternal notch and $5 \mathrm{~cm}$ below the tip of left mastoid process. The obliquity of the ligature mark is from right to left in the front and sides of the neck. The total neck circumference is $34 \mathrm{~cm}$.
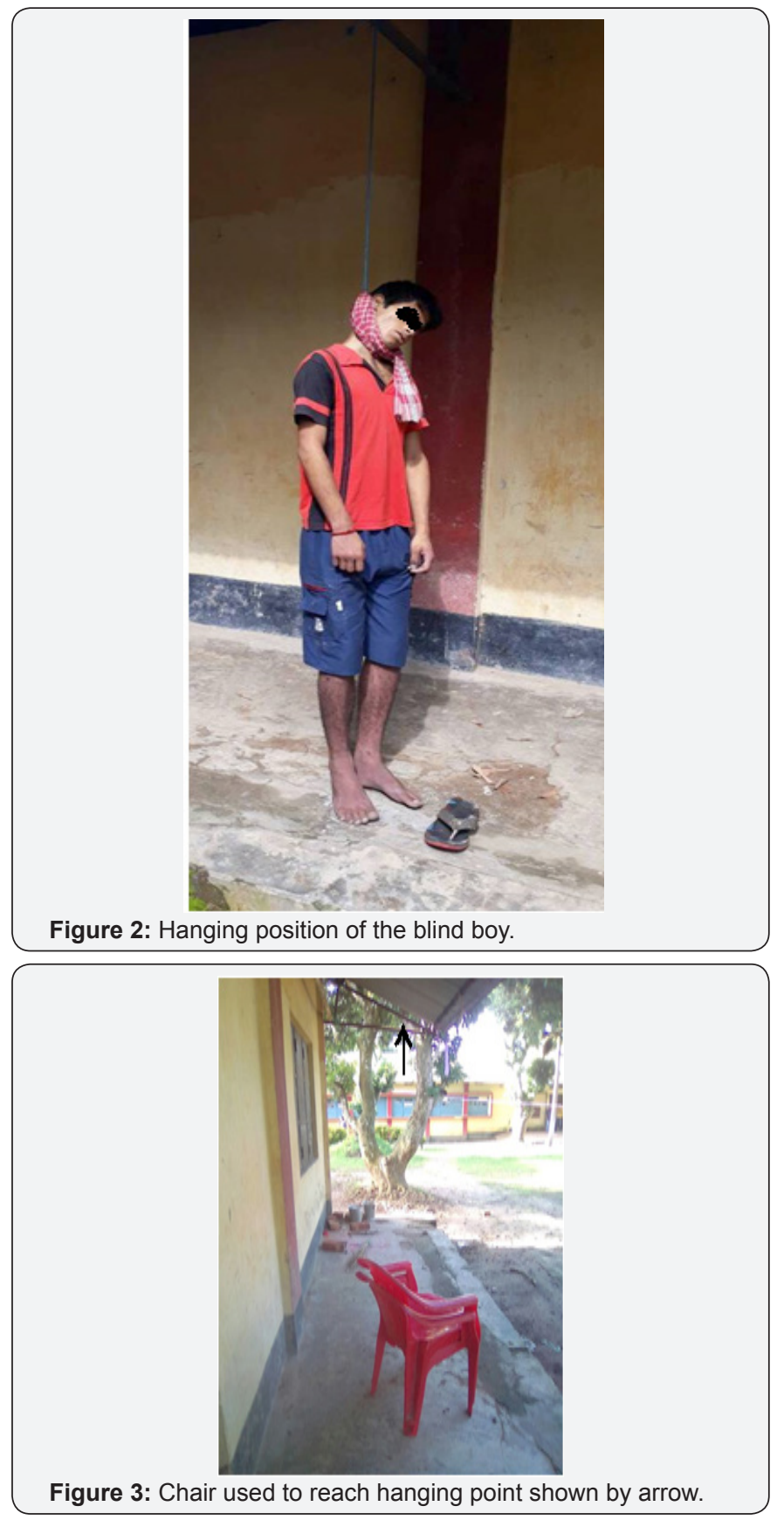
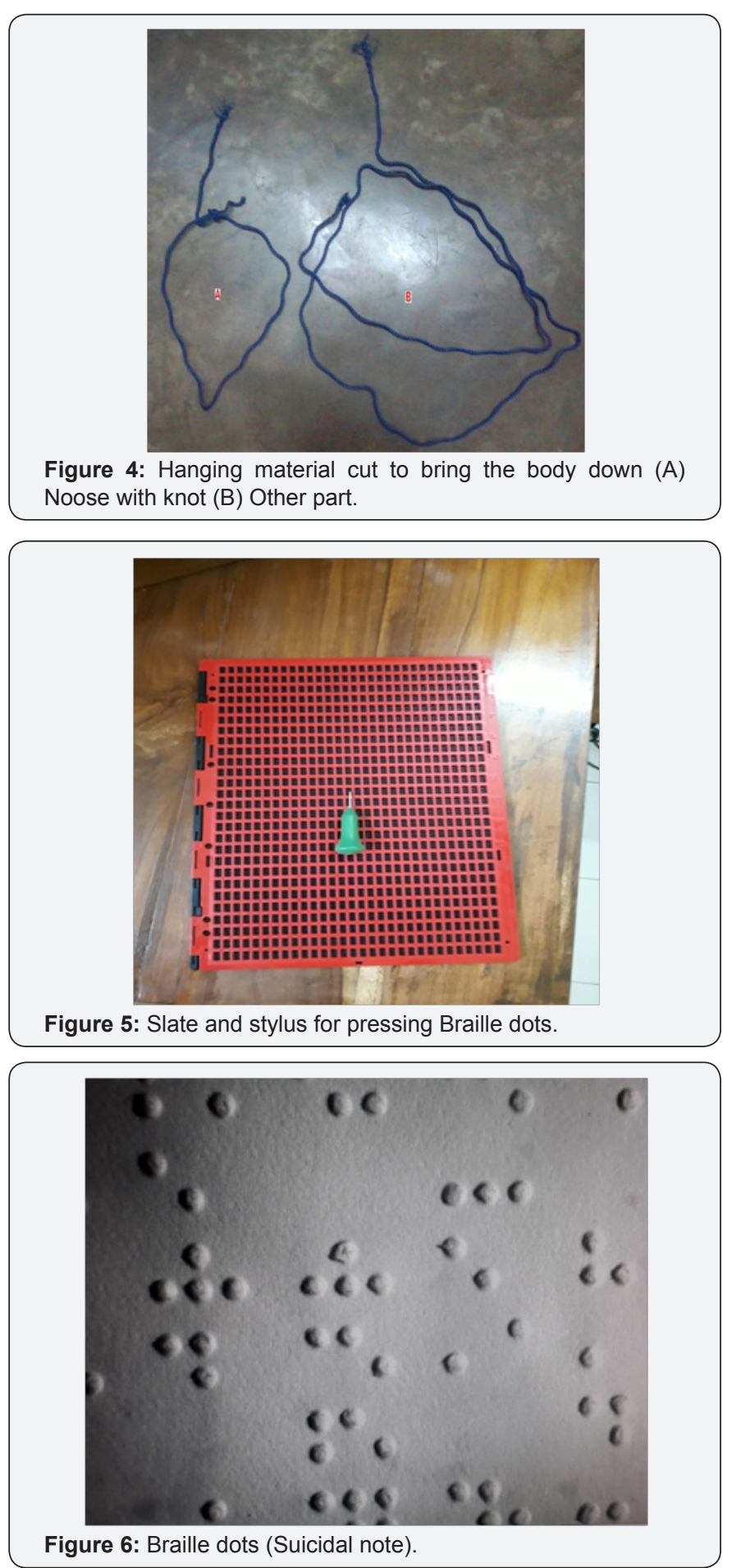

Internal: On dissection, the skin and subcutaneous tissues are pale and glistening and there is no contusion in the layers of the muscles of the neck. The hyoid bone, thyroid cartilages and cricoid cartilages are intact. The intimas of the carotid arteries are intact. Few echymoses are present along the margins of the ligature mark. Peeling of skin is present along the margins of the ligature mark. The injuries mentioned above are antemortem in nature and fresh in duration. The cause of death is asphyxia as a result of suicidal hanging. 


\section{Conclusion}

Post analysis of the hanging body in undisturbed condition and autopsy findings supported by suicidal note (Braille writing) could prove the death was due to suicidal hanging. Though the suicidal note (Braille dot) having identical embossed dots looks alike but based on pressure, shape, spacing available in admitted writing (Braille dots) of the deceased could be corroborated to be written by the deceased (blind man) in this case. Suicide is a multifaceted and complex event. In this case the suicidal note reveals that the victim was struggling with feeling of mental distress and lacking capacity to bear suffering. In addition, his negative thoughts and lack of support were unbearable burden of life resulted in violent manifestation that is suicidal hanging.

\section{Acknowledgement}

The authors are thankful to Mr. Jayanta Malakar for his technical assistance during crime scene management.

\section{References}

1. Mass M, Cisyns P, Meltzere H (1993) Seasonality in violent Suicide but not in nonviolent suicide or homicide. Am J Psychiatry 150: 1380-1385.

2. Pal A, Pratihari HK (2017) Suicide or Homicide? A case Study, J Forensic Sci \& Criminal Inves 3(2): 1-3.

3. Pal A, Pratihari HK, Unusual hanging: A Case report, J Forensic \& Crime studies, 4(1):1-3.

4. Suicide prevention (SUPRE) World Health Organization (2012)

5. http://www.who.int/mental_health/prevention/suicide/ suicideprevent/en/

6. http://www.dailymail.co.uk/news/article-2208864/Deaf-blind-man63-hanged-grief-yards-body-wife-died-heart-attack.html
This work is licensed under Creative Commons Attribution 4.0 License

DOI: $10.19080 /$ JFSCI.2017.04.555650 